\title{
ANALISIS SEMIOTIKA DALAM RUBRIK IKLAN MOBIL HARIAN JAWA POS
}

\author{
Isnaini Anniswati Rosyida \\ Universitas Islam Darul Ulum (Unisda) Lamongan \\ Telp.081332452830 \\ isnainianniswati@yahoo.co.id
}

\begin{abstract}
This research was conducted with the aim to examine the sign that was built in the Jawa Pos daily car ad. Verbal and visual mark is intensive use in advertising. Semiotics is used by the authors to analyze several car ads in expressing visual and verbal sign, how they are used to communicate, persuade, or convince the reader. The method used is descriptive qualitative. Author collect, sort and classify the data, then the data were analyzed using semiotic. And finally the author presents the results. The results of this research showed the kinds of figurative marks in daily car ads Java Pos. .In connection with the results obtained, the authors suggest that manufacturers better understand the theories of semiotics in ad creation, especially in the daily car ads Java Pos. Conduct research various advertising needs to be done by collecting data from print and electronic media as a comparison on this study.
\end{abstract}

Keywords: semiotic analysis, rubric car ads, Jawa Pos daily

Abstrak: Penelitian ini dilakukan dengan tujuan untuk meneliti adanya tanda yang dibangun dalam iklan mobil harian Jawa Pos. Tanda verbal dan visual merupakan hal yang intensif digunakan dalam iklan. Semiotika digunakan oleh penulis untuk menganalisa beberapa iklan mobil dalam mengungkapkan tanda verbal dan tanda visual, bagaimana tanda itu digunakan untuk berkomunikasi, membujuk, atau meyakinkan pembaca. Metode yang digunakan adalah deskriptif kualitatif. Penulis mengumpulkan, memilah, dan mengelompokkan data yang ada, kemudian data dianalisis menggunakan teori semiotika. Dan akhirnya penulis menyajikan hasilnya. Hasil dari penelitian ini memperlihatkan adanya macam-macam tanda figuratif dalam iklan mobil harian Jawa Pos.Sehubungan dengan hasil yang didapat maka penulis menyarankan agar produsen lebih memahami tentang teori-teori semiotika dalam pembuatan iklan terutama iklan mobil di harian Jawa Pos.Melakukan penelitian berbagai iklan perlu dilakukan dengan mencari data baik dari media cetak maupun media elektronik sebagai bahan pembanding atas penelitian ini.

Kata kunci : analisis semiotika, rubrik iklan mobil, harian Jawa Pos

PENDAHULUAN

Bahasa jurnalistik, khususnya bahasa surat kabar terealisasi dalam ragam bahasa yang berbeda dengan ragam bahasa lain. Perbedaan satu ragam bahasa dengan ragam bahasa lain bersifat kuantitatif dan performatif. Ragam bahasa jurnalistik memiliki ciri yaitu (1) proyeksi. (2) bahasa objektif.

kontraksi dan (4) metafora. Bahasa terstruktur berdasarkan fungsi pemakaian bahasa (Haliday,1994; Martin,1992). Dengan ini pengertian bahasa yang digunakan untuk pemberitaan atau iklan dan jurnalistik memiliki struktur yang 
berbeda dengan bahasa yang digunakan untuk tujuan lain.

Pada era globalisasi,media massa mempunyai peran yang sangat penting untuk menyampaikan berita, gambaran umum serta berbagai informasi kepada masyarakat luas. Sebagai penyampai informasi, ia mempunyai kemampuan untuk berperan dalam membentuk opini publik dan dapat dipandang sebagai factor yang menentukan proses-proses perubahan. Fungsi media massa yang penting menurut Muis (2000: 111) adalah memelihara identifikasi anggota-anggota masyarakat dengan nilai-nilai dan simbol-simbol utama masyarakat yang bersangkutan.

Penelitian ini membahas tentang tanda-tanda yang terdapat pada rubrik iklan mobil pada surat kabar. Semiotika disini digunakan sebagai pendekatan untuk menganalisis media-media dengan asumsi bahwa media itu dikomunikasikan melalui seperangkat tanda. Penelitian ini berusaha memahami makna-makna dari tanda-tanda yang tersembunyi di dalam rubrik iklan mobil pada harian Jawa Pos yang meliputi penanda dan petanda,ikon, indeks, serta simbol. Sedangkan teori yang digunakan dengan mengkombinasikan teori Ferdinand De Saussure dan teori Charles Sanders Pierce. Tujuan dalam penelitian ini diharapkan dapat bermanfaat dalam upaya peningkatan mutu dalam mencermati analisis semiotik yang terdapat dalam bahasa iklan yang dapat memperkaya ilmu bahasa, khususnya analisis semiotik serta dapat memberikan informan kepada masyarakat periklanan agar mampu memaknai penggunaan tanda-tanda yang ada pada sebuah iklan.

Semiotika berasal dari kata Yunani: semeion, yang berarti tanda (Tinarbuko, 2009). Semiotika adalah ilmu yang mempelajari tanda (sign), berfungsinya tanda, dan produksi makna. Tanda adalah sesuatu yang bagi seseorang berarti sesuatu yang lain. Semiotika (semiotics) didefinisikan oleh Ferdinand de Saussure di dalam Course in General Linguistics, sebagai "ilmu yang mengkaji tentang tanda sebagai bagian dari kehidupan sosial". Implisit dalam definisi de Saussure adalah prinsip, bahwa semiotika sangat menyadarkan dirinya pada aturan main (rule) atau kode sosial (social code) yang berlaku di dalam masyarakat, sehingga tanda dapat dipahami maknanya secara kolektif (Piliang, 2003: 256). Semiotika adalah ilmu yang mengkaji tanda dalam kehidupan manusia. Artinya, semua yang hadir dalam kehidupan dilihat sebagai tanda, yaitu sesuatu yang harus diberi makna (Hoed, 2008:3). Semiotika pada perkembangannya menjadi perangkat teori yang digunakan untuk mengkaji kebudayaan manusia (Hoed, 2008:4).

Tanda berada dimana-mana, kata adalah tanda, demikian pula gerak isyarat, lampu lalu lintas, bendera, dan sebagainya. Segala sesuatu dapat menjadi tanda, dengan demikian berarti tanpa tanda kita tidak dapat berkomunikasi. (Zoest, 1996:vii). Tanda bisa berarti sesuatu bagi seseoran jika hubungan yang berarti ini diperantarai oleh interpretan (Eco dalam Sobur, 2004:109). Tanda sebenarnya representasi dari gejala yang memiliki sejumlah kriteria seperti : nama (sebutan), peran, fungsi, tujuan, dan keinginan. Tanda bisa berada di seluruh kehidupan manusia yang penuh makna (meaningful action) seperti teraktualisasi pada bahasa, religi, ilmu pengetahuan (Budianto, 2001:16).

Hal yang terpenting dalam proses semiosis adalah bagaimana makna muncul dari sebuah tanda ketika tanda ini digunakan saat orang berkomunikasi (Sobur, 2002:15).

Secara etimologis, simbol (symbol) berasal dari kata Yunani "sym-ballein" 
yang berarti melemparkan bersama suatu (benda, perbuatan) dikaitkan dengan suatu ide. (Hartoko \& Rahmanto,1998: 133 dalam Sobur,2013:155). Ada pula yang menyebutkan "simbolos", yang berarti tanda atau ciri yang memberitahukan sesuatu hal kepada seseorang (Herusatoto, 2000:10). Simbol terjadi berdasarkan metonimi yakni nama untuk benda lain yang berasosiasi atau yang menjadi atributnya dan metafora yaitu pemakaian kata atau ungkapan lain untuk objek atau konsep lain berdasarkan kias atau persamaan (Kridalaksana, 2001:136-138).

Hal pokok pada teori Saussure yang cukup penting adalah prinsip yang menga takan bahwa bahasa itu adalah system tanda, dan setiap tanda itu tersusun dari dua bagian, yakni signifier (penanda) dan signified (petanda). Petanda adalah aspek mental dari bahasa (Bertens dalam Sobur, 2013:46). Yang mesti diperhatikan adalah bahwa dalam tanda bahasa yang konkret, kedua unsur tadi tidak bisa dilepaskan. Tanda bahasa selalu mempunyai dua segi: penanda atau petanda.

Dalam proses komunikasi manusia, penyampaian pesan menggunakan bahasa. Bahasa terdiri atas simbol-simbol yang dimaknai agar terjadi komunikasi yang efektif. Manusia memiliki kemampuan dalam mengelola simbolsimbol: menerima, menyimpan, mengolah, dan menyebarkan simbolsimbol (Samovar, 1981:135 dalam Vera. 2014:6).

Iklan merupakan jenis komunikasi nonpersonal, senada dengan beberapa definisi iklan, yang antara lain :"Iklan adalah komunikasi komersil dan nonpersonal tentang sebuah organisasi dan produk-produknya yang ditransmisikan ke suatu khalayak target melalui media yang bersifat massal, seperti televise, radio, koran, majalah, direct mail, reklame luar ruang, atau kendaraan umum" (Lee \& Johnson, 2007:3 dalam Vera (2014:43)

\section{METODE PENELITIAN}

Jenis penelitian ini adalah penelitian deskriptif kualitatif, yaitu penelitian yang bersifat atau memiliki karakteristik, bahwa datanya dinyatakan dalam keadaan sewajarnya atau sebagaimana adanya dengan mempergunakan cara kerja yang sistematis, terarah dan dapat dipertanggungjawabkan sehingga tidak kehilangan sifat ilmiahnya (Nawawi, 1996:175). Analisis kualitatif, data yang dianalisis bukan data berupa angkaangka, tetapi berupa kata-kata (Mahsun, 2005: 257).

Strauss dan Corbin (dalam Sujarweni: 2014:19)menyatakan bahwa penelitian kualitatif adalah jenis penelitian yag menghasilkan penemuanpenemuan yang tidak dapat dicapai (diperoleh) dengan menggunakan prosedur-prosedur statistik atau cara-cara lain dari kuantifikasi (pengukuran).

Teknik analisis data yang diterapkan adalah teknik identifikasi, kemudian diseleksi dan dikelompokkan sesuai dengan kerangka teori yang digunakan dalam penelitian ini. Akhirnya data tersebut diolah dan dianalisis dengan langkah-langkah sebagai berikut: (1) mengumpulkan iklan mengelompokkan iklan (3) menganalisis iklan berdasarkan analisis semiotik

\section{HASIL PENELITIAN DAN PEMBAHASAN}

\section{Analisis Semiotika: Tanda Verbal,} Tanda Visual, Penanda, dan Petanda

Iklan mobil dalam harian Jawa Pos ini mengandung unsur semiotika dalam deskripsi penanda (signifier) dan petanda (signified) menurut Saussure, seperti yang dikutip Pradopo (1991:54) : "Tanda sebagai kesatuan dari dua bidang yang 
tidak dapat dipisahkan seperti halnya selembar kertas, dimana ada tanda disana ada sistem. Artinya, sebuah tanda ( berwujud kata atau gambar) mempunyai dua aspek yang ditangkap oleh indera kita yang disebut dengan signifier, bidang petanda atau bentuk dan aspek lainnya yang disebut signified, bidang petanda atau konsep atau makna. Aspek kedua terkandung di dalam aspek pertama. Jadi petanda merupakan konsep atau apa yang dipresentasikan oleh aspek pertama. Penanda terletak pada tingkapan ungkapan (level of expression) dan mempunyai wujud atau merupakan bagian fisik seperti bunyi, huruf, kata , gambar, warna, obyek dan sebagainya. Sedang petanda terletak pada level of content ( tingkatan isi atau gagasan ) dari apa yang diungkapkan melalui tingkapan ungkapan, hubungan antara kedua unsur melahirkan makna”.

\section{Analisis Semiotika iklan Truk "Dutro Hino300 series"}

Truk ini sangat cocok digunakan untuk membantu menjalankan bisnis di tengah geliat pembangunan dan banyaknya kawasan industri pada saat ini. Untuk memenuhi permintaan konsumen terutama dari kalangan industri dan perusahaan distributor barang konsumen yang membutuhkan membawa barang ringan dalam jumlah besar tetapi memiliki bodi ramping. Truk ini juga dapat melintasi kelas jalanan manapun, mulai jalan arteri sampai jalan lingkungan pemukiman warga serta memenuhi kebutuhan konsumen dengan truk ringan yang tangguh daya angkut besar, serta andal untuk menunjang aktivitas bisnis. "Kapasitas angkutan yang besar mmungkinkan truk ini bisa membawa barang yang dalam sekali angkut".Jalanan luar kota tidak selalu sama landainya dan seringkali justru banyak sekali tanjakan yang harus dilewati baik tanjakan yang rendah maupun yang tinggi dan panjang. Tenaga yang kuat dibutuhkan untuk mengatasi tanjakan ini, karena seringkali kita melihat banyak truk yang mogok karena tidak kuat menanjak. Hal ini yang membawa produsen mensiasati bagaimana cara agar truk yang akan dipasarkan bisa mngatasi hal itu dan menjadikan andalan dari produknya sehingga diminati oleh calon pembeli.

Memakai truk jenis ini dapat meningkatkan volume angkut, artinya kita dapat mengangkut atau membawa barang yang kapasitas atau muatan yang lebih banyak.Sehingga, apabila seorang pebisnis membutuhkan dapat membawa muatan yang kapasitasnya sangat banyak dapat dilakukan dengan hanya membawa barang atau muatan hanya dalam sekali angkut. Dengan demikian dapat mempersingkat waktu, dan menghemat bahan bakar.karena tidak beberapa kali mengangkut barang atau muatan.Hanya sekali saja dalam mengangkut.Sehingga dapat efisienkan para pebisnis di kawasan industri. Rear Overhang atau bagian dari chasis (rangka) pada truk ini mempunyai penambahan panjang, sehingga sangat cocok untuk truk angkutan barang yang ringan dengan volume yang besar atau banyak.

\section{Analisis semiotika iklan "Daihatsu New Terios"}

Tanda verbal yang kita dapatkan dari iklan ini adalah Judul "New Terios Explore your Adventurous Imagination" memberikan pemahaman bahwa jenis mobil ini membuktikan melakukan penjelajahan. Dengan melalui penjelajahan berarti terios melakukan petualangan, sehingga dengan demikian mobil ini berhasil membuktikan ketangguhannya sebagai sahabat berpetualang di berbagai kondisi jalan. 
Batu karang yang tinggi menjulang menandakan kekokohan.Yang ingin diusung oleh produsen adalah mobil yang kuat sekuat batu karang.Mobil dengan batu karang yang tinggi disini diartikan bahwa mobil ini canggih dapat dikendarai sampai ke beberapa tempat yang sangat sulit dilalui seperti batu karang yang sangat tinngi.Disini menandakan bahwa tempat ini memang sangat sulit dilalui.

Sedangkan Langit berawan di atas memberikan nuansa bahwa alam memang liar dan sewaktu-waktu dapat menjadi ganas dan liar. Keliaran alam dapat terjadi jika awan hitan terlihat seperti terlihat pada gambar mendadak berarak cepat dan kemudian hujan turun deras ataupun laut yang terlihat tenang, dan tiba-tiba bergelora karena ombak besar dating bergulung-gulung.Sedang mobil berjalan di malam hari menandakan bahwa perjalanan berpetualang dilakukan pada malam hari, atau petualangan dilakukan sampai malam tiba.Namun jika kita melishat pada keadaan mobil yang masih bagus tidak terjadi cacat atau halhal yang mengakibatkan keadaan mobil menjadi rusak.

\section{Analisis Semiotika Iklan Mobil Sedan “All- New Lexus ES"}

Berdasarkan tanda verbal dan visual dari iklan ini, kita dapatkan penanda-petanda berupa "All New Lexus Es, the next level of Elegance and progressive luxury", yang ingin ditonjolkan oleh produsen selaku pengirim pesan kepada konsumen. 'Teks' sebenarnya merupakan perwujudan dari bahasa Maksud lisan yang secara semiosis dapat diwujudkan ke dalam teks. Bahasa lisan terikat pada "aku, disini, sekarang".Jika menjadi teks sistem acuannya berubah dan menjadi pemilik pembaca.Sedangkan Eco melihat teks sebagai sebuah karya terbuka yang memungkinkan penafsiran ganda.(Hoed, 2004: 10).

Kata 'Exceptional Comfort' yang artinya adalah mobil yang memberikan kenyamanan.Disini mendatangkan petanda tempat kita dapat menikmatinya dengan santai tanpa gangguan kebisingan dan dapat melakukan aktivitas sesuai dengan keinginan kita.Nyaman disini yang dimaksud adalah apabila kosumen mengendarai mobil dapat menikmati dengan senang, mobil ini jika dalam perjalanan tidak memberikan keguncangan.

Kalimat 'The Power of Hybrid' mengandung arti bahwa mobil ini memakai 2 tenaga yaitu dengan bahan bakar bensin dan bahan bakar listrik.Mobil ini menggabungkan 2 kekuatan dengan tenaga listrik dan bahan bakar minyak. Menggunakan 2 kekuatan tersebut tidak merusak lingkungan dan udara yang bersih, sehingga dapat membantu untuk mencegah polusi udara, yang menjadikannya sebagai mobil ramah lingkungan. Perancangan iklan ini bukan saja untuk memenuhi kebutuhan serta asosiasi-asosiasi yang dapat menggugah selera, agar bertindak sesuai dengan keinginan pengiklan namun penawaran disini juga disiapkan untuk menciptakan selera tertentu terhadap produk yang ditawarkan (Sobur, 2004: 121). Pesan yang tampak disini tidak dibuat hanya mengiklan suatu fungsi atau kegunaan saja akan tetapi lebih menonjolkan kreatifitas yang memberikan suatu nilai lebih pada produk ini.

Mobil ini menggabungkan motor listrik dengan mesin bensin untuk membuat salah satu kendaraan hybrid yang efisien dan ramah lingkungan di dunia. Sebuah kendaraan yang diciptakan untuk menunjang gaya hidup modern yang nyaman serta konsumsi bhn bakar yang ramah lingkungan. Oleh karena itu, 
kendaraan ini menggunakan energy listrik yang disimpan dalam baterai untuk menjalankan mobil di motor listrik dalam rentang kecepatan rendah. Juga menggunakan mesin gas atau bensin di kisaran kecepatan dimana ia beroperasi dengan efisiensi energi yang baik dengan performa tangguh. Mobil yang memiliki mesin kombinasi antara konvensional dengan sistem motor listrik ini diklaim dapat menjadi solusi untuk penghematan konsumsi bahan bakar minyak (BBM).

\section{Analisis Semiotik Iklan Jenis Pick Up "Suzuki Carry Pick Up"}

Judul 'Suzuki Carry Pick-up lebih banyak lebihnya' dengan tulisan menggunakan huruf kapital yang berukuran tinggi $1 \mathrm{~cm}$, tebal 0,5 sampai $1 \mathrm{~cm}$ dalam iklan tersebut dimaksudkan untuk memperjelas apa yang ingin disampaikan oleh pengiklan yaitu produsen dan juga untuk mencuri perhatian dari target yang dituju dalam hal ini tentunya calon pelanggan. Judul tersebut sebagai penanda memberikan pemahaman bahwa Suzuki carry pick up digunakan untuk menemani perjalanan bisnis konsumen agar makin lancar dan menguntungkan usaha bisnisnya. Mobil ini sangat cocok digunakan untuk melakukan pengembangan usaha dari para pebisnis.Mobil sangat cocok untuk angkutan barang-barang yang diangkut dengan bak terbuka. Karena dengan memiliki mobil jenis ini alat angkut yang digunakan oleh para pebisnis dapat memperlancar usahanya dan sangat menguntungkan bagi usaha para pebisnis.Sehingga mobil jenis ini paham betul ILMU nya bisnis. Maksud dari kata ILMU tersebut adalah $\mathrm{I}=$ 'Irit bensin dan perawatannya' bahan bakar yang digunakan oleh mobil ini sangatlah hemat, irit. Dengan servis yang murah dan mudah, servis dapat dilakukan di bengkel-bengkel mobil biasa. Suku cadangnya juga murah dan banyak, banyak suku cadang yang tidak orisinil tetapi sangat murah, sangat mudah perawatannya. $\mathrm{L}=$ 'Lama umur pakainya'

Pada kalimat 'Lama umur pakainya' artinya bahwa mobil jenis ini awet, serta bandel. Karena mesin yang ditanamkan pada mobil ini memang mesin dengan kualitas yang sudah tidak bisa diragukan lagi.Mesin mobil ini tangguh dan bandel sehingga menjadi andalan bagi para pebisnis.Karena dengan memiliki mesin yang sangat bagus, mobil ini tidak gampang rusak, sehingga awet memiliki umur yang sangat panjang.M = 'Muatannya banyak' Kalimat 'Muatannya banyak' mengandung arti bahwa mobil ini memiliki kabin yang sangat luas sehingga dapat membawa atau mengangkut muatan yang cukup banyak.Apapun barang sejumlah berapapun dapat diangkut. Dengan bisa membawa banyak muatan atau barang sehingga terjadilah efisiensi waktu karena dengan hanya mengangkut barang atau muatan cukup satu kali saja, karena mobil bisa mengangkut banyak barang..Selain itu juga efisiensi biaya karena dengan sekali angkut dapat mengirit bahan bakar.U = 'Untung diujung',Untung diujung' artinya para pebisnis memiliki mobil ini memperoleh banyak keuntungan. Karena dengan irit bensin dan perawatan, lama umur pakai, muatannya banyak, para pebisnis mendapatkan untung yang sangat banyak dalam menjalankan usaha bisnisnya. Mobil ini untuk penunjang usaaha, mobil yang bisa diandalkan sebagai alat untuk kemajuan usaha pebisnis. Bukan hanya harga yang ramah di kantong serta mendukung bisnis, harga jual kembali mobil ini juga cukup tinggi. Jika mobil ini akan dijual, harga jualnya sangat stabil, jika dibandingkan dengan harga jual mobil yang lain yang rata-rata harganya merosot tajam. 
Penanda 'mobil' ini akan menimbulkan konsep mental tau petanda yang tidak selalu sama pada pembaca yang satu dengan pembaca yang lain. Bisa saja petnda yang timbul berupa mobil sedan, mobil balap, mobil truk , mobil bak terbuka, dan lain sebagainya. Dengan demikian pada tulisan "Suzuki Carry Pick up", bagi yang sudah meneganal jenis yang dimaksud dengan Carry Pick up, tentu akan mudah membayangkan mobil mana yang dimaksud. Tetapi untuk yang belum mengenal tetap hanya gambaran umum dari mobil saja yang mereka punyai.Dan kalimat 'Segera kunjungi dealer Suzuki terdekat' adalah ajakan atau hal menyuruh kepada pembaca untuk mengunjungi tempat penjualan yang terdekat.

Mobil merujuk pada alat angkut. Gambar mobil merupakan tanda yang berupa gambar dari bendanya. Pada tahap interpretant kita akan dapatkan salah satu penafsirannya, kalau mau angkut barang pakai mobil yang seperti ini yaitu mobil dengan bak terbuka, bisa memuat banyak barang.

\section{Analisis Semiotik Iklan Mobil Great New Xenia}

Kalimat 'More Stylish' memberikan anggapan bahwa mobil ini mempunyai bodi mobil yang sangat bergaya, mengikuti mode sekarang tidak ketinggalan jaman. Mempunyai tampilan yang terlihat sangat mewah dan bergaya serta memiliki tampilan warna yang mewah. Mobil ini terlihat semakin elegan dan mewah karena berkat desain baru dengan warna yang mempunyai aksen elegan. Kalimat more stylish dipakai untuk meyakinkan pembaca bahwa meskipun kendaraan ini bukan kendaraan sedan atau kendaraan mewah tapi bisa juga memberikan bodi atau bentuk yang bergaya atau mempunyai kesan yang mewah.

Sedang 'More Efficient \& Powerful' merupakan penanda yang mempunyai arti bahwa mesin mobil baru ini mempunyai tenaga yang lebih besar serta menggunakan bahan bakar yang lebih hemat. Meskipun mobil dikendarai pergi ke tempat yang jauh, hanya mengisi tangki bensin sekali saja. Mobil ini telah menggunakan system injeksi bahn bakar yang akan membuat konsumsi bahan bakar semakin irit. Spesifikasi pada kendaraan ini juga dibekali dengan tangki bahan bakar yang berukuran cukup besar sehingga mampu menampung banyak. Dengan kapasitas tangki bahan bakar tentunya tidak akan takut kehabisan bahan bakar saat bepergian

Tanda visual berupa mobil Great New Xenia melewati jalan yang menanjak menandakan bahwa mobil ini sangatlah kuat untuk bepergian ke tempat yang ada tanjakannya. Seperti melakukan perjalanan dari kota Padang menuju Danau Toba. Jalan yang dilalui pada daerah tersebut sangatlah curam,melewati ring road yang terkesan lebar dan agak lurus. Anak merasakan kenyamanan yang luar biasa ketika menikmati perjalaanan. Karena kabin mobil yang sangat luas dan mobil tidak memberikan guncangan yang sangat berarti dalam perjalanan. Dengan demikian rasa nyaman didapat karena aktivitas yang dilakukannya dimobil tidak terganggu dengan tidak adanya guncangan-guncangan. Seorang anak biasanya bermain dimanapun dia berada, dan duduk diam akan merasa bosan. Pada gambar diperhatikan bahwa anak kecil ini dapat melakukan kegiatan bermain di dalam mobil dengan tanpa guncangan. Sehingga ia merasa nyaman bermain dalam mobil. Tanda visual berupa wanitadengan bodi mobil Great New Xenia yang bergaya mengkonotasikan 
bahwa mobil ini mempunyai bodi yang sangat bergaya.

\section{Tanda dalam Rubrik Iklan Mobil Harian Jawa Pos \\ Ikon}

Ikon merupakan suatu tampilan dalam bentuk gambar dan kita dapat melihat bahwa tanda ikonik berhubungan dengan objeknya dengan kemiripan terhadap objek tadi.Jandi tanda ikonik trmasuk tanda linguistik dan tanda yang berbentuk gambar yaitu lukisan, gambar, dan foto.

Dalam iklan-iklan mobil, kita biasanya melihat foto dari berbagai jenis mobil yang tersedia. Tanda tadi dapat dilengkapi pada :

Iklan Mobil jenis Truk "Hino Dutro 300 series" dengan truk yang mempunyai ruang kargo yang panjangnya $4.260 \mathrm{~mm}$

Pada ikon ruang kargo panjang $4.260 \mathrm{~mm}$ memberikan asumsi bahwa mobil jenis ini memuat lebih banyak barang.

Iklan Mobil jenis SUV "New Daihatsu Terios" dengan batuan karang yang terjal

Pada ikon batuan karang yang terjal memberikan asumsi bahwa mobil jenis ini dapat digunakan untuk berpetualang dapat melewati tempat-tempat yang terjal dengan banyak batu karang.

Iklan mobil jenis sedan "All New LEXUS ES" dengan kabin mobil yang mewah dan luas

Pada ikon kabin mobil yang mewah dan luas memberikan asumsi bahwa mobil jenis ini merupakan mobil yang merupakan jenis mobil yang mempunyai kesan mewah.

Iklan Mobil Jenis Pick up "Suzuki Carry Pick Up" dengan dua tipe atau jenis mobil.

Pada ikon dua tipe atau jenis mobil memberikan asumsi bahwa produsen atau pembuat iklan memberikan dua pilihan dengan tipe atau jenis mobil yang berbeda.

Iklan Mobil Jenis minibus "Daihatsu Great New Xenia" dengan pemandangan yang bagus yang ditawarkan dalam iklan.

Pada ikon pemandangan yang bagus memberikan asumsi bahwa dengan mengendarai mobil jenis ini dapat menikmati pemandangan yang bagus. Dalam iklan mobil kita hampir selalu melihat gambar mobil yang merupakan ikon dari mobil yang ditawarkan.Gambar mobil merupakan ikon yaitu tanda yang berupa gambar atau foto yang dirujuk pada bendanya.

\section{Indeks}

Indeks adalah tanda yang berdasarkan relasi sebab dan akibat atau koneksi gabungan antara tanda dan objeknya. Kata yang memiliki hubungan indeksikal masing-masing memiliki ciri utama secara individual. Ciri tersebut antara satu dengan yang lain berbeda dan tidak dapat saling menggantikan. Dalam tanda visual, indeks sering kita temukan dalam gambar-gambar iklan tadi.

\section{Data Hino Dutro 300 series}

Kita melihat kendaraan truk ini mempunyai ruang kargo $4.260 \mathrm{~mm}$. Dengan memiliki ruang kargo yang cukup panjang dengan mudah kita mengangkut barang konsumen dalam jumlah yang besar.Jika kendaraan ini mempunyai ruang yang panjang, maka dapat mengangkut barang dalam jumlah yang sangat besar dengan mudah. Hanya sekali angkut untuk membawa barang konsumen tersebut. Jadi gambar kendaraan yang mempunyai kabin cukup panjang ini merupakan indeks dari kata 'lebih panjang bisa muat lebih banyak' yang terdapat dalam judul dari iklan ini.

\section{Data New Daihatsu Terios}

Gambar mobil yang berjalan di daerah yang banyak batu karang.Mobil 
yang berjalan di daerah yang sangat menguji adrenalin para petualang. Serta berhasil membuktikan ketangguhannya sebagai sahabat berpetualang di berbagai kondisi jalan.Melakukan perjalanan pada malam hari serta dengan ketangguhannya mobil dapat melakukan ekspedisi dan sukses melewati medan yang sangat menantang,menyusuri alam yang liar. Ketangguhan mobil petualang tersebut merupakan indeks dari kata 'Adventure' atau 'petualangan'.

\section{Data All New LEXUS ES}

Dalam iklan ini digambarkan sebuah mobil yang memiliki kabin yang luas, eksterior dan interior yang serba mewah dan elegan. Dengan memiliki jok pengemudi dan penumpang terbuat dari kulit berwarna mewah serta jok yang empuk dan dalam iklan terdapat gambar pada stir kemudi yang sangat elegan dengan warna coklat mewah. Dalam iklan ini diperlihatkan interior dan eksterior yang sangat apik merupakan indeks dari 'elegance and luxury' atau 'elegan dan mewah'.

\section{Data Suzuki Carry Pick Up}

Gambar empat mobil pick up yang memiliki 2 jenis yang berbeda. Mobil tersebut memiliki bak belakang yang terbuka. Mobil dapat mengangkut barang dagangan atau muatan yang sangat banyak dari para pebisnis. Gambar empat mobil bak terbuka tersebut merupakan indeks dari 'Muatan banyak".

\section{Data Daihatsu Great New Xenia}

Pada iklan terdapat gambar mobil yang melakukan perjalanan melewati pemandangan, jalanan yang sangat terjal, dengan banyak tanjakan. Biasanya mobil akan mogok kalau jalanan yang dilaluinya banyak tanjakan. Disini mobil yang dapat melalui beberapa rintangan tersebut merupakan indeks dari 'ketangguhan'.

\section{Simbol}

Sebuah simbol mengacu pada objeknya bukan karena kemiripan atau hubungan sebab antara objek dan tandanya tapi berdasarkan kesepakatan sosial. Dalam iklan merek dagang merupakan simbol. Mercedes melambangkan keanggunan, kemewahan dan prestos. Dalam penelitian ini, simbol yang digunakan :

\section{Data Hino Dutro 300 series}

'Truk Hino Dutro 300 series" merupakan simbol mobil dengan bak terbuka untuk mengangkut barang dengan ukuran yang lebih besar dari pick up.

\section{Data New Daihatsu Terios}

"SUV New Daihatsu Terios" merupakan simbol mobil berpetualang yang biasanyadigunakan untuk orang berlima dengan bagian belakang untuk muat barang bawaan,tetapi ada juga yang digunakan untung orang bertujuh.

\section{Data All New LEXUS ES}

"Sedan All New LEXUS ES" simbol mobil dengan aksen mewah dan elegan yangbiasanya dengan tempat duduk untuk empat sampai lima orang

\section{Data Suzuki Carry Pick Up}

"Pick Up Suzuki Carry" merupakan simbol mobil dengan bak terbuka digunakan untuk mengangkut barang dengan ukuran yang lebih kecil daripada truk.

\section{Data Daihatsu Great New Xenia}

"MPV Daihatsu Great New Xenia" merupakan simbol mobil yang bisa digunakan dengan kapasitas 7 sampai 8 orang penumpang, mobil ini sedikit lebih besar dari SUV

\section{SIMPULAN}

Tanda yang ditemukan dalam iklan mobil di harian Jawa Pos yang terbit bulan April dan Mei 2016, meliputi penanda, petanda, ikon, indeks, dan simbol. Sebagai penanda dan petanda, maka dibangun oleh tanda-tanda ini 
dengan tujuan "menarik perhatian" pembaca dan mempengaruhinya untuk mempertimbangkan produk yang diiklankan. Tanda-tanda yang didapat dari analisis semiotik pada iklan mobil kesemuanya mengandung maksud menarik perhatian khalayak untuk membujuk para konsumen agar menerima sarannya bersedia membeli produk-produk yang ditawarkan oleh produsen. Iklan merupakan salah satu bentuk komunikasi antara pembuat iklan dengan pembaca, baik sebuah komunikasi untuk mempromosikan barang, jasa maupun pelayanan masyarakat.Bentuk komunikasi yang dimaksud berupa tanda-tanda verbal dan nonverbal yang terdapat dalam iklan.Melalui iklan juga, dapat mengetahui pola atau konsep berfikir dari suatu masyarakat tertentu. Sedangkan untuk tanda yang ada dalam rubrik iklan harian Jawa Pos yang meliputi ikon, indeks dan simbol dari produk yang dihadirkan oleh pihak produsen juga mempunyai arti untuk mempengaruhi atau menarik konsumen atau pembaca agar mau membeli produk-produk yang telah ditawarkannya. Tanda-tanda yang ada dibalik iklan mobil dikaji pada setiap gambar, tulisan serta warna yang ada pada keseluruhan tampilan iklan tersebut, yang dikaji dengan menggunakan metode analisis semiotika.

\section{DAFTAR PUSTAKA}

Bertens, K. 2001. Filsafat Barat Kontemporer Prancis. Jakarta: Gramedia Pustaka Utama

Budianto, Irmayanti M. 2001. Aplikasi Semiotika pada Tanda Nonverbal makalah pada pelatihan semiotika 23-26 September 2001. Jakarta: Pusat Penelitan Kemasyarakatan dan Budaya Lembaga Penelitian

Universitas Indonesia (LPUI)

Haliday, M.A.K dan Ruqaiya Hasan .1992. Bahasa,konteks, dan teks. Yogyakarta: Gajah Mada University Press

Hartoko, Dick \& B. Rahmanto. 998. Kamus Istilah Sastra. Yogyakarta: Kanisius

Herusatoto, Budiono. 2000. Simbolisme dalam Budaya Jawa. Yogyakarta: Hanindita Graha Widia

Hoed , Benny H . 2008. Semiotika dan Dinamika Sosial Budaya .Jakarta : FIB. UI

Kridalaksana, Harimurti.2001. Kamus Linguistik. Edisi Ketiga. Jakarta: Gramedia Pustaka Utama

Muis, A 2001 Indonesia di Era Dunia Maya : Teknologi Informasi dalam Dunia Tanpa Batas : Bandung; Remaja Rosdakarya

Nawawi , H, Hadari. 1995, Metode Penelitian Bidang Sosial. Yogyakarta: Gadjah Mada University Press

Piliang, Amir Yasraf, 2003, Semiotika Komunikasi Yogyakarta Jalasutra

Pradopo, Rachmat Djoko .1991 Beberapa Teori Sastra, Metode Kritik, dan Penerapannya.Pustaka Belajar Yogyakarta

Sobur, Alex, 2002, Analisis Teks Media Remaja Rosdakarya Bandung

Sobur, Alex, 2013, Semiotika Komunikasi Remaja Rosdakarya Bandung

Tinarbuko,Sumbo, 2009. Semiotika Komunikasi Visual, Yogyakarta, Jalasutra

Van Zoest, Aart. 1996 Semiotika.Jakarta Yayasan Sumber Agung

Vera, Nawiroh. 2014 Semiotika dalam Riset Komunikasi, Bogor, Ghalia Indonesia. 